\title{
Research on Interaction Design of Multi-Screen Interactive Products Based on Mobile Terminal
}

\author{
Xinxiong Liu, Congmei Huang,Haiping Zhao, \\ WensiLi \\ Huazhong University of Science and Technology Wuhan, \\ Hubei 430074, P. R. China
}

\begin{abstract}
As the state promote the triple play actively, many companies and research institutes have conducted in-depth research and development of the multi- screen interactive products. In this paper, the author designed a new multi-screen interactive product, that started from multi-screen interactive background and analysis of many existing product ,and this product combined with the wimo project participated in during the internship at China Mobile Research Institution.
\end{abstract}

Keywords-triple play. multi-screen interaction. wimo. interaction design

\section{INTRODUCTION}

Multi-screen interaction means it can be mutually compatible across operations between the different operating systems (IOS, ANDROID, WIN7, WINDOWS, $\mathrm{XP}$, VISTA etc.), and various terminal devices (smart phone, smart tablet, computer, TV), it can perform a series of operations like the transmission of digital multimedia ( HD video , audio, images ) content ,synchronization of different screen display content, the control of devices and soon, by the connection of wireless network[1].In the Internet Age, family business market contains a huge value ,but its pattern has not yet formed. At present there are two kinds of the most common application of multi-screen interactive technology ,first, the multi-screen interactive technology to TV products and the second is the integration of multi-screen interactive terminal direction. The performance of the former is not enough rich applications because of the carrier in the form of its own has certain limitations. Multi-screen interactive terminal, which is a professional tailor-made for multi-screen interactive technology, it can realize cross-platform operation, allow the user to have a broader and more free user experience. And it could realize the function that intelligent TV totally can not reach. So the latter will be able to dominate the triple-play market in the future.

\section{THE CURRENT SITUATION AND DEVELOPMENT TREND OF MULTI-SCREEN INTERACTION}

With the development of communication technology, information technology and TV Technology, the digital TV, a new media form of communication rapidly growing popularity[2].Subsequently, the "moving" and "multi-screen integration" business needs began to gradually appear in user behavior ,the video content providers, network operators, service providers, manufacturers and other audio-visual equipment terminal of "big video" Digital TV operators have begun to focus on the layout of the mobile Internet, and focus on the development of integrated multi-terminal cross-screen video services, they have launched the network terminal products and services based on multi-screen interactive technology. So "multi- screen integration " will become an important service form of the triple play[3].However this field is currently in its infancy, the products are many and disorderly, and it has not formed a unified system of industrial chain.

Multi-screen interactive technology appeared in 2000,the frequency and the extent of multi-screen interaction continued to expand after 10 years of development, ,multi-screen interaction may become an important service form of the triple play. ZhangXinsheng, the Secretary-General of China Institute of Communications, said:' there are four major trends in the development of the Internet in the future:1.Human-computer interaction, from pre-control to control body;2.Multi-screen interaction, mobile phone, IPAD, TV, smart terminals and so on;3.Cloud enhanced fusion;4.Wearable Terminal.'

For the user, the strong demand of multi-screen interaction is not just the formal "fit" ,the more important demand is the wonderful experience that brought by the "connotation" of product itself. This pair of Internet service providers, has put forward higher requirement of technology about multi -screen interaction. As you can see from the figure 1, many domestic major companies competing to develop their own multi-screen interactive technology since 2006, and 2013 is the fastest growing year, more than ten companies was in the production of their own multi-screen interactive products.

TABLE I. THE DEVELOPMENT LINE OF MULTI-SCREEN INTERACTION FROM 2006 TO 2014

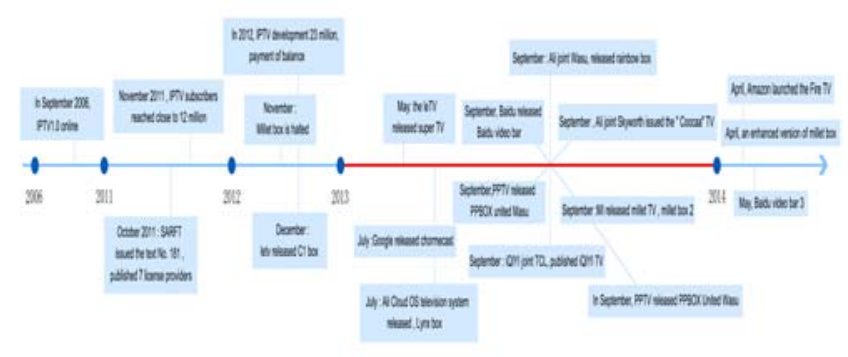




\section{DEMAND ANALYSIS , SCENE SIMULATION, COMPETITIVE ANALYSIS AND RESEARCH OF INNOVATION}

In 2013,Huang Gawei, vice president of Samsung's Internet applications and services center, said:' Multi-screen interaction is not the future, but the demand that already existed. The problem is that we do not have a good application to meet this demand for now.' In the future consideration of multi-screen interaction, it will be very important that how to innovate around consumers. In this year, the field of Internet has realized the people demand for multi-screen interaction, which makes the major manufacturers developed their degree of desire to reach a high point. China Mobile Research Institute did not want to fall behind, and self-developed the Wimo which is a multi-screen interactive terminal product based on different terminals. This paper mainly study the wimo of the mobile terminal products in android.

\section{A. Demand analysis}

- Simplicity

With the rapid development of high-tech, people's life becoming more and more intelligent, more and more simple, simple design can be able to set aside enough space for the user and they will use their own life to fill the space, so as to create a richer, more meaningful experience [4].

- Comprehensiveness

According to the survey, the biggest demand of people is the family entertainment, at the same time there are many other aspects of the functional requirements like: game competition and sharing in the same screen, video sharing, music sharing, photo sharing, document sharing ,sharing in the same screen and so on. It follows that users' degree of acceptance and integration of new product is high.

- Fluency

At the technical level, it can be found that the user has a very high demand to the product throughout the fluency and quality from the user experience of the existing multi-screen interactive product.

- Fashion

The users' first sensing of product is visual perception. T he full expression of the product must include these three aspects :beauty, design style and the expression of the image. Multi-screen interaction belongs to the emerging high-tech products, so the sense of science and technology and futuristic is the focus of design need to express.

\section{B. Scene simulation}

- Scene I : In the workplace

Step1:In the conference room,father was letting mobile phone and micro-cast synchronous display the PPT with wireless and explaining the material content.

Step2:Father discussed materials' issues with other four colleagues , and the other four would pass their PC screen to the micro-cast.

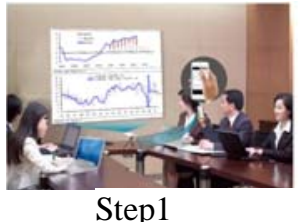

Step1

- Scene II : On the way home

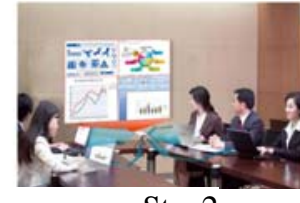

Step2
Step1:Dad needed navigation ,he used navigation software on the phone $\mathrm{C}$ to plan route and then pushed the navigation screen and voice on the phone to the vehicle tablet computer A with wireless.

Step2:Mom opened the phone $D$, select view the photographs and pushed to the car tablet $\mathrm{B}$, then select the phone $\mathrm{D}$ and pushed the music to wireless speakers.

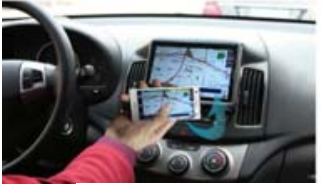

Step1

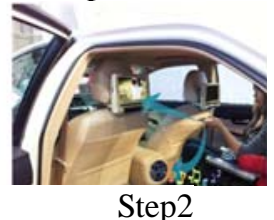

Step2
- SceneIII: Home entertainment

Step1:Yueyue was using the phone A in the living room, receiving a reverse pass screen picture from a set-top box and using the touch screen to control the set-top box side to run the game(like Angry Birds).

Step2:The mobile phone has a video incoming call from grandfather, displayed the video screen to the set-top box after connect, at the same time, shooting son's image with phone camera.

Step3: After the call, grandfather sent a text message to Yueyue with a video link that is the animation clip of Crazy primitive man, son saw the SMS and opened link to watch cartoons.

Step4: Mother pushed two different kinds of audio and video programs to the micro-cast in bedroom and the PC in study room at the same time with phone $\mathrm{B}$ (like micro-cast receives variety, $\mathrm{PC}$ receives the sports programs ).Mom, Dad in the bedroom and study, respectively, with their mobile phone $\mathrm{B}, \mathrm{C}$ to control the program content that pushed by phone A(like Volume, progress, pause, play ).

Step5: Son wanted to get his game scores sent to parents to enjoy then he used the phone A to control set-top box as the sender and send this game screen with the set-top box to micro-investment and PC equipment.

Step6: The parents came to the living room to play games with his son. Son, mother, father respectively used their mobile phone $\mathrm{A} / \mathrm{B} / \mathrm{C}$ and let each game the phone with the screen display to set-top boxes.

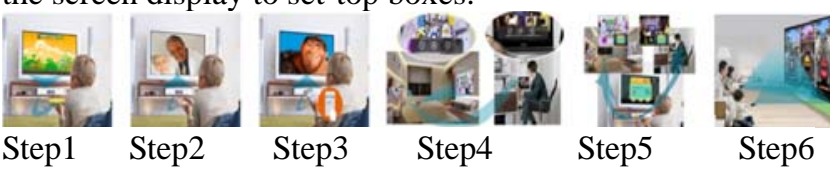

C. Competitive analysis

Competitive Analysis is a valuable tool for understanding strategic market positioning,its emphasis is function, instead of the target [5].In the trend of the triple play, currently flooded with a variety of digital products 
with multi-screen interactive technology on the market and emerged new multi-screen interactive applications [6], they have a mature technology but the user experience is poor,so the overall effect is not ideal.At present, there are mainly four kinds of multi-screen interactive products:Video software based multi-screen interactive software ; multi-screen interactive technology to television products;multi-screen interactive technology to mobile phone products; multi-screen interactive software about integrated direction.

- Video software based multi-screen interactive software

Video has gradually became the first major application of the Internet , according to statistics of iResearch ,Internet people in China , the number of online video has reached 350 million , penetration rate is $65.1 \%$ [7].Several existing video software have realized multi -screen interactive technology, including Thunder, Youku,Tudou , Sohu , etc.This kind of multi-screen interaction is easy to operate but its range is narrow,only limited in the field of video.

- Multi-screen interactive technology to TV products

Zhang Yaqin, Microsoft's senior vice president , said in the next five years, the Smart TV will become a hot IT industry,and the industry chain is gradually forming[8].Now the Smart TV with this technology is very hot,which is easy to operate and has high stability but the realization form of multi-screen interaction among different brands are different, and this does not give a unified specification to user.

- Multi-screen interactive technology to mobile phone products

The intelligent mobile phone has became the center to promote the development of multi-screen interaction because of its performance is sufficient to meet the needs of multi-screen interaction.Mobile phones of each big brand has been with multi-screen interactive technology,there is no need to install third-party software. But there are drawbacks like tedious and program instability in these built-in multi-screen interaction.

- Multi-screen interactive software about integrated direction

Almost no software developed in this type of multi-screen interactive terminal,and developers have focused on the development of multi -screen interaction within their respective fields.At present, only found multi-screen interactive Turner (screen + ) mobile terminal,it cannot be found in Android and Apple products in the application of the product. These show that the current market is extremely lacking of a unified and integrated system.

\section{Research of innovation}

It can be seen from the analysis of competing products about multi-screen interactive technology ,a common problem about the market system is that the system is disorder , jumbled content.Professor and author ,Donald Norman once said: "When the technology meets the basic requirements, user experience would begin to dominate everything"[9].So the important direction of this study is user-centric, build a complete system which has consistent user experience, concise and unified interface,low latency,interference,low-cost,equipment interoperability , low delay, anti-interference, low cost and Intercommunication equipment,and it will serve the China Mobile 's own business needs.

\section{THE MAIN FUNCTION AND INTERACTION DESIGN FRAMEWORK OF WIMO MULTI-SCREEN INTERACTION}

\section{A. The main function of wimo multi-screen interaction}

China Mobile self-developed Wimo,the multi-screen interactive products.Its product positioning is: 1. Build a complete multi-screen interactive system to meet the needs of individual user experience, which can realize the intelligent matching, multi-screen family sharing, custom heart synchronized with video, virtual functions and so on.2.Integrated Wimo, China 's self-developed wireless multi-screen interactive technology,in multi business.

TABLE 2. DISPLAY FUNCTION OF WIMO MULTI-SCREEN INTERACTION

Display function of Wimo multi-screen interaction

\begin{tabular}{|c|c|c|c|}
\hline $\begin{array}{c}\text { Functional } \\
\text { classification }\end{array}$ & $\begin{array}{l}\text { Media } \\
\text { sharing }\end{array}$ & $\begin{array}{l}\text { Screen } \\
\text { sharing }\end{array}$ & Control \\
\hline $\begin{array}{c}\text { Technical } \\
\text { characteristic } \\
\text { s }\end{array}$ & $\begin{array}{l}\text { Transfer the } \\
\text { media } \\
\text { content data } \\
\text { stream to the } \\
\text { playback } \\
\text { device }\end{array}$ & $\begin{array}{l}\text { The mobile } \\
\text { terminal } \\
\text { screen } \\
\text { synchronous } \\
\text { transmission } \\
\text { to the big } \\
\text { screen } \\
\text { equipment }\end{array}$ & $\begin{array}{l}\text { Transmit the } \\
\text { remote } \\
\text { control } \\
\text { signaling } \\
\text { to device } \\
\text { by the } \\
\text { mobile } \\
\text { terminal }\end{array}$ \\
\hline $\begin{array}{l}\text { Application } \\
\text { of scene }\end{array}$ & $\begin{array}{l}\text { Watch } \\
\text { online video, } \\
\text { browse the } \\
\text { local media }\end{array}$ & $\begin{array}{c}\text { Document } \\
\text { sharing, } \\
\text { audio and } \\
\text { video } \\
\text { sharing, } \\
\text { games, } \\
\text { comics, etc. }\end{array}$ & $\begin{array}{c}\text { Virtual } \\
\text { keyboard } \\
\text { and mouse, } \\
\text { multimedia } \\
\text { control, } \\
\text { virtual } \\
\text { gamepad, } \\
\text { etc. }\end{array}$ \\
\hline $\begin{array}{c}\text { Device } \\
\text { requirements }\end{array}$ & $\begin{array}{c}\text { The sender } \\
\text { configuratio } \\
n \\
\text { performance } \\
\text { requirements } \\
\text {; The } \\
\text { receiver } \\
\text { needs to } \\
\text { support a } \\
\text { variety of } \\
\text { media } \\
\text { formats }\end{array}$ & $\begin{array}{l}\text { The sender } \\
\text { with } \\
\text { real-time } \\
\text { multimedia } \\
\text { coding } \\
\text { capability ; } \\
\text { the } \\
\text { receiving } \\
\text { end of } \\
\text { media } \\
\text { compatibilit } \\
\text { y } \\
\text { requirement } \\
\text { s low }\end{array}$ & $\begin{array}{l}\text { The sending } \\
\text { end, } \\
\text { receiving } \\
\text { end } \\
\text { configuratio } \\
\mathrm{n} \\
\text { performance } \\
\text { requirement } \\
\text { s are low }\end{array}$ \\
\hline
\end{tabular}




\section{B. The design framework of wimo multi-screen interaction}

TABLE 3. FUNCTION STRUCTURE OF MEDIA SHARING

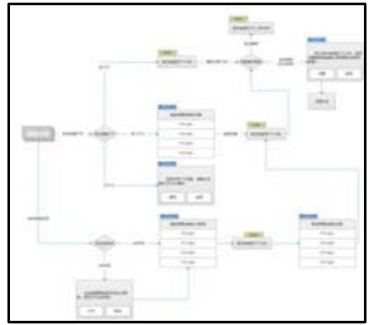

TABLE 4. FUNCTION STRUCTURE OF SCREEN SHARING

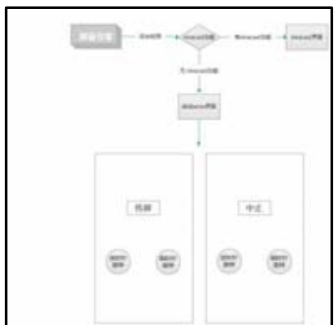

TABLE 5. WIMO INTERACTION FLOW( WHEN A CLIENT CONNECTS OTHER DEVICES THAN WIMO,MEDIA SHARING INTERFACE IS DIVIDED INTO THREE TABS:PICTURES, MUSIC AND VIDEO )

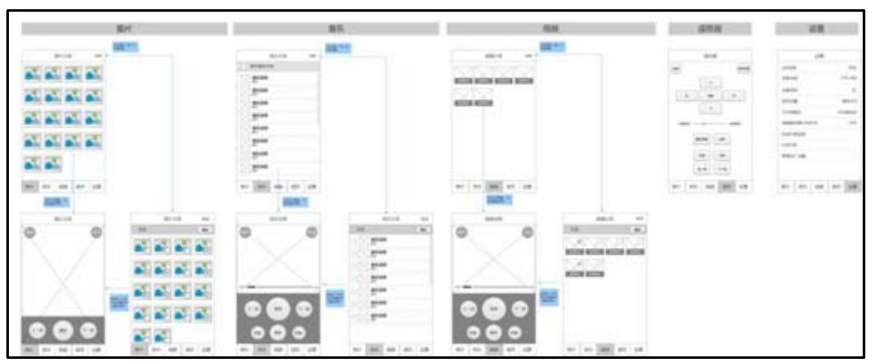

\section{CONCLUSION}

Wimo makes the phone became " wireless set-top box ",which can share real-time mobile content on a large screen in television and other equipment.And it also can strengthen the control on the " triple play" multimedia inlet and flow of phone,make the phone became the core equipment of" triple play ".The product positioning and design style of Wimo interactive design are also depend on China Mobile 's corporate positioning. The interactive process for technical has not achieved the most concise for the reason of technology, this will be an important research direction for design team in the future.

\section{REFERENCES}

[1] Ye Dan.Implementation Raiders of " Multi-screen interactive"[OL].http://tech.sina.com.cn/t/2013-08-01/08208595516.s html .2013

[2] Liu Weinan.Research of digital TV interactive interface design based on multi-screen interaction[D].Southeast University .2014

[3] Li Yuandong.How to save the TV? Multi screen broadcasting should realize the cross network cross screen fusion[OL].http://www.dvbcn.com/2013/06/21-101184.html.2013

[4] Giles Colborne.Supreme simplicity : four interactive design strategy[M].Posts and Telecom Press.2012

[5] Jon Kolko.Interactive Design Meditations[M].China Machine Press.2012

[6] Wan Xinru.Research on interaction design of different terminal screen interactive platform[D].Tianjin University .2012

[7] Eastmoney.com.Multi-screen interactive era[OL].http://finance.eastmoney.com/news/1373,201307103051003 49.html.2013

[8] Wang Jiecong,Zhang Yaqin.The smart TV will be the IT hot in the next years[OL].http://news.cheaa.com/2012/0113/308242.shtml.2012

[9] Stephen P.Anderson.Seductive Interaction Design[M].Posts and Telecom 